\title{
Changes in plasma phospholipid fatty acids and their relationship to disease activity in rheumatoid arthritis patients treated with a vegetarian diet
}

\author{
BY MARGARETHA A. HAUGEN ${ }^{1}$, JENS KJELDSEN-KRAGH ${ }^{2}$, KRISTIAN S. \\ BJERVE ${ }^{3}$, ARNE T. HØSTMARK ${ }^{4}$ AND ØYSTEIN FØRRE ${ }^{1}$ \\ ${ }^{1}$ Oslo Sanitetsforening Rheumatism Hospital, Oslo, Norway \\ ${ }^{2}$ Institute of Immunology and Rheumatology, National Hospital, Oslo, Norway \\ ${ }^{3}$ Department of Chemical Chemistry, Regional Hospital, University of Trondheim, Trondheim, \\ Norway \\ ${ }^{4}$ Department of Preventive Medicine, University of Oslo, Norway
}

(Received 9 September 1993 - Revised 3 December 1993 - Accepted 1 February 1994)

\begin{abstract}
In a controlled clinical trial we have recently shown that patients with rheumatoid arthritis (RA) improved after fasting for 7-10 d and that the improvement could be sustained through 3.5 months with a vegan diet and 9 months with a lactovegetarian diet. Other studies have indicated that the inflammatory process in RA can be reduced through manipulation of dietary fatty acids. A switch to a vegetarian diet significantly alters the intake of fatty acids. Therefore, we have analysed the changes in fatty acid profiles of the plasma phospholipid fraction and related these changes to disease activity. The concentrations of the fatty acids $20: 3 n-6$ and $20: 4 n-6$ were significantly reduced after $3 \cdot 5$ months with a vegan diet $(P<0.0001$ and $P<0.01$ respectively), but the concentration increased to baseline values with a lactovegetarian diet. The concentration of $20: 5 n-3$ was significantly reduced after the vegan diet $(P<0.0001)$ and the lactovegetarian diet periods $(P<0.01)$. There was no significant difference in fatty acid concentrations between diet responders and diet non-responders after the vegan or lactovegetarian diet periods. Our results indicate that the changes in the fatty acid profiles cannot explain the clinical improvement.
\end{abstract}

Fatty acid profile: Vegetarian diet: Rheumatoid arthritis

The concentrations of fatty acids in serum phospholipids and phosphatidylcholine have been found to be altered in patients with rheumatoid arthritis (RA; Bruderlein et al. 1981; Jacobsson et al. 1990) and in patients with juvenile chronic arthritis (JCA; Johansson et al. 1986) compared with healthy controls. In these studies the proportion of the saturated fatty acids was found to be significantly increased, and the proportion of linoleic acid $(18: 2 n-6)$ significantly reduced. This altered fatty acid profile is most likely to be a result of the inflammatory process, since no difference in dietary intake has been found between groups of patients with RA or JCA and healthy controls or patients with osteoarthritis (Kowsari et al. 1983; Johansson et al. 1986; Haugen et al. 1992). This notion is also supported by the negative correlation between the proportion of $18: 2 n-6$ and acute-phase reactants (Creactive protein and orosomucoid; Jacobsson et al. 1990).

It has been shown that the fatty acid composition of plasma and tissue phospholipids with change to reflect dietary intake. This has stimulated rheumatologists to undertake supplementation studies with $\gamma$-linolenic acid $(18: 3 n-6)$ and polyunsaturated long-chain fatty acids of the $n-3$ series in attempts to modulate the immune system through a reduction of arachidonic acid (20:4n-6; Ziff, 1983). Arachidonic acid is the precursor of the 
proinflammatory eicosanoids, whereas dihomo- $\gamma$-linolenic acid $(20: 3 n-6)$ and eicosapentaenoic acid $(20: 5 n-3)$ are the precursors of less inflammatory eicosanoids. Thus, during an inflammatory stimulus the macrophages will produce less of the prostaglandins and leukotrienes with high inflammatory potential (Endres et al. 1989; Santoli et al. 1990). Dietary supplementation with 20:3n-6 (Belch et al. 1988; Pullman-Mooar et al. 1990) and with 20:5n-3 together with docosahexaenoic acid (22:6n-3; Kremer et al. 1987; KjeldsenKragh et al. 1992) has been shown to reduce clinical symptoms in patients with RA.

Attention has also been paid to oleic acid (18:1n-9), which constitutes $72 \%$ of the fatty acids in olive oil. Reductions of pain and articular index have been found in a study in which olive oil was used as placebo (Brzeski et al. 1991). Furthermore, a reduced incidence of RA has been reported to be associated with an increased intake of olive oil (Linos et al. 1991). The mechanism by which oleic acid exerts its effects in RA patients has yet to be elucidated but, since oleic acid can substitute for the unsaturated fatty acids in the phospholipid fractions, it is possible that oleic acid exerts its effect through reduced availability of the substrates for eicosanoid production (Vossen et al. 1993).

The proportion of 20:4n-6 in different phospholipid fractions has been found to be either changed or unaltered as a result of vegan and lactovegetarian diets (Kirkeby \& Bjerkedal, 1968; Sanders et al. 1978; Phinney et al. 1990; Sanders \& Roshanai, 1992). These diets contain more $18: 2 n-6$ than omnivorous diets, but they are devoid of $20: 4 n-6,20: 5 n-3$, 20:6n-3 and 22:6n-3 (Roshanai \& Sanders, 1984). This implies that the eicosanoid precursors must be produced endogenously from $18: 2 n-6$ and $18: 3 n-3$ respectively. If the endogenous production of $20: 4 n-6$ from $18: 2 n-6$ cannot compensate for the absence of 20:4n-6 in the diet, the precursor of the proinflammatory eicosanoids would be reduced. It is possible that this could explain the beneficial effect of vegetarian diets in patients with RA.

Lipid peroxides are believed to be generated from unsaturated fatty acids by $O$ radicals during the inflammatory process (Rowley et al. 1984). The $O$ radicals are thought to play a part in the disease process by mediating oxidative damage (Lunec et al. 1981). It has been reported that fasting and consumption of a vegetarian diet for 3 weeks reduced the concentration of lipid peroxidation products measured as thiobarbituric acid-reacting substances (TBARS) in patients with fibromyalgia (Høstmark et al. 1993). Antioxidants, which are abundantly present in vegetarian diets, may explain the reduced concentration of the TBARS (Abdulla et al. 1981). This could perhaps also contribute to the alleviation of the disease symptoms in patients with RA during treatment with a vegetarian diet.

In a controlled single-blind clinical trial we found that the disease activity decreased in patients with RA who ate a vegetarian diet (Kjeldsen-Kragh et al. 1991). This study has been extended by determining the changes in the fatty acid profile of the plasma phospholipids during the vegetarian diets and by examining whether the changes of the fatty acid concentrations were associated with concomitant changes in subjective and/or objective variables of disease activity. For the same purpose we also measured the concentrations of the serum lipid peroxidation products.

\section{SUBJECTS AND METHODS}

\section{Study design}

The study was a prospective, single-blind, controlled clinical trial designed to investigate possible impact on disease activity of fasting and a l-year vegetarian diet in patients with RA (Kjeldsen-Kragh et al. 1991). The patients were randomized to either a diet group or a control group. The study was approved by the regional scientific ethical committee. 
Subjects

Fifty-three omnivorous RA patients with active disease were enrolled in the study (fortyfive female and eight male; Kjeldsen-Kragh et al. 1991). All patients satisfied the criteria of the American Rheumatism Association for classical or definite RA (Ropes et al. 1958). Twenty-seven patients were allocated to the diet group (mean age 51 years) and twenty-six patients to the control group (mean age 55 years). In the diet group, one patient terminated the study after 1 month and a further three patients after 4 months. Altogether twenty-three patients continued on the lactovegetarian diet for more than 3 months. In the control group, one patient terminated the study after 1 month and a further four patients after 4 months in the study. Blood was drawn and dietary and clinical assessments were carried out at inclusion, after 1 month, after 4 months, and at the time point at which the patients left the study.

\section{Treatment}

The patients in the diet group began the study with a 4-week stay at a health farm where they fasted for 7-10 days. The fast consisted of herb teas, garlic, vegetable broths, decoction of potatoes and parsley and vegetable juices of carrots, beets and celery. Thereafter, the patients reintroduced a 'new' food item every 2 nd day, but kept a strict gluten-free vegan diet during the following 3.5 months. After 3.5 months they switched to a lactovegetarian diet. The patients in the control group began the study with a 4-week stay at a convalescent home. They were told to continue their normal diet and were not given any dietary instructions, except for two patients who were given low-fat diet guidelines because of elevated serum cholesterol values (over $8 \mathrm{mmol} / 1$ ).

Since it is known that a vegan diet leads to a low intake of vitamin $D$, the patients were told to take vitamin-D supplementation $(10 \mu \mathrm{g}$ cholecalciferol/d). The patients who took cod-liver oil supplementation on a regular basis before entering the study were told to continue with the cod-liver oil supplementation throughout the study $(5 \mathrm{ml}$ cod-liver oil/d $=10 \mu \mathrm{g}$ cholecalciferol/d). Altogether five patients in the diet group and five patients in the control group used cod-liver oil supplementation on a daily basis during the whole study period.

\section{Blood analyses}

Venous peripheral blood samples were collected before the morning meal, between 08.00 and 10.00 hours. Serum samples were frozen $\left(-20^{\circ}\right)$ for subsequent analysis of serum TBARS and plasma samples were frozen $\left(-70^{\circ}\right)$ for subsequent analysis of the fatty acids in the plasma phospholipids. The TBARS were measured as malondialdehyde-reactive products (Kosugi et al. 1989). The concentration of plasma phospholipid acids was measured according to the method described by Bønaa et al. (1990). These results are presented as $\mathrm{mmol} / \mathrm{l}$ and as a percentage of the total phospholipid fatty acids. During the lactovegetarian diet period the data were collected from five patients after 3 months, one patient after 6 months and seventeen patients after 9 months on a lactovegetarian diet. All these data were treated as if they had been collected at the same time point. The justification for this is that fatty acid concentrations in plasma phospholipids respond rapidly to changes in the dietary intake (Grønn et al. 1991).

\section{Dietary assessments}

Food intake was assessed by $24 \mathrm{~h}$ recalls at the same time as the blood samples were drawn. The amount consumed was given in household measurements. Energy, total fat and fatty acid intake were calculated using the software package 'FIBER' based on the Norwegian Food Composition Tables (Statens Ernæringsråd, 1988). 


\section{Characterization of responders/non-responders}

The following variables were used to distinguish between diet responders and diet nonresponders: number of swollen joints, Stanford Health Assessment Questionnaire Index (HAQ; Fries et al. 1980), pain score on a visual analogue scale, number of tender joints, patients global assessment and erythrocyte sedimentation rate (ESR). These variables have been assigned as core measures for clinical trials in RA (Tugwell et al. 1993). A two-grade improvement on the scale for patient's global assessment was defined as a substantial improvement and for the other five variables $\geqslant 20 \%$ improvement compared with baseline values was required (Paulus et al. 1990). To be characterized as diet responders the patients had to have improved substantially in at least three of these core variables at each of the last three clinical examinations.

\section{Statistical analysis}

Data are expressed as means and standard deviations. For the fatty acids $20: 5 n-3,22: 5 n-3$ and $22: 6 n-3$ only the data from the patients not using cod-liver oil is included, since the concentrations of these fatty acids were significantly higher in the group using cod-liver oil. To test within-group differences of plasma phospholipid fatty acids and serum lipid TBARS a paired $t$ test was used. The distributions of plasma phospholipid $18: 2 n-6,18: 3 n-3$, $20: 5 n-3$ and $22: 6 n-3$ were skewed, and $\log$ transformed values were used in these analyses. To test between-group differences an unpaired $t$ test was used. Since the dietary intakes of most of the fatty acids during the treatment period were non-normal and since no suitable transformation could be found, the Wilcoxon rank-sum test was used to test for possible differences in fatty acid intake. The Mann-Whitney test was used to analyse the possible differences between the patients who used or did not use cod-liver oil supplementation at the time of inclusion. This test was also used to compare the concentrations of fatty acids between diet responders and diet non-responders after the vegetarian diet periods.

To test the overall group differences for TBARS an analysis of covariance (ANACOVA) was used with the baseline values as covariate. This was done because the serum concentrations of the lipid peroxidation products in the diet and control groups were significantly different at the time of inclusion (Montgomery, 1984). To study a possible association between the different fatty acids and disease activity, ANACOVA was performed. In these models the number of swollen joints, the number of tender joints and ESR were run as dependent variables respectively. Either the concentration or the proportion of the fatty acids were run as covariates (Kleinbaum et al. 1988). $P$ values below 0.05 were considered to be statistically significant. The NCSS software package was used (Hintze, J. L., Kaysville, Utah, USA).

\section{RESULTS}

Compliance with the diet could not be evaluated by any objective means. However, during the health farm stay the patients had scarce opportunities to deviate from the diet, living in a close community with other patients and the health farm personnel. During the strict gluten-free vegan diet, four patients confessed intake of dairy products once or twice. The infringement consisted of sour cream as dressing and one patient had one glass of skimmed milk once. One male patient who found the vegan diet very hard to follow ate elk meat four times. During the modified lactovegetarian diet period, five patients admitted to having eaten meat on two occasions, but the diet was mostly broken by intake of fish at special occasions such as weddings and anniversaries. 
Table 1. Intakes of energy $(M J / d)$, protein and fat (\% energy) by rheumatoid arthritis patients consuming a vegetarian diet, compared with controls $\uparrow$

(Mean values and standard deviations)

\begin{tabular}{|c|c|c|c|c|c|c|c|c|}
\hline & \multicolumn{2}{|c|}{$\begin{array}{c}\text { At } \\
\text { inclusion }\end{array}$} & \multicolumn{2}{|c|}{$\begin{array}{l}\text { After } \\
1 \text { months }\end{array}$} & \multicolumn{2}{|c|}{$\begin{array}{l}\text { After } \\
4 \text { months }\end{array}$} & \multicolumn{2}{|c|}{$\begin{array}{c}\text { After } \\
7-13 \text { months }\end{array}$} \\
\hline & Mean & SD & Mean & SD & Mean & SD & Mean & SD \\
\hline \multicolumn{9}{|l|}{ Diet group $\ddagger$} \\
\hline$n$ & \multicolumn{2}{|c|}{27} & \multicolumn{2}{|c|}{27} & \multicolumn{2}{|c|}{26} & \multicolumn{2}{|c|}{23} \\
\hline Energy intake $(\mathrm{MJ} / \mathrm{d})$ & $7 \cdot 1$ & 1.5 & $5 \cdot 0^{* * * *}$ & $2 \cdot 1$ & 6.8 & $3 \cdot 0$ & $6 \cdot 1$ & $1 \cdot 6$ \\
\hline Protein (\% energy) & $14 \cdot 5$ & $2 \cdot 4$ & $10 \cdot 2^{* * *}$ & $2 \cdot 8$ & $10 \cdot 7^{* * *}$ & $2 \cdot 4$ & $13 \cdot 5$ & 3.9 \\
\hline Fat ( $\%$ energy) & $35 \cdot 8$ & $7 \cdot 4$ & $27 \cdot 2 * *$ & $13 \cdot 4$ & $29 \cdot 3^{* *}$ & $11 \cdot 0$ & $31 \cdot 2$ & $8 \cdot 5$ \\
\hline \multicolumn{9}{|l|}{ Control group } \\
\hline$n$ & \multicolumn{2}{|c|}{26} & \multicolumn{2}{|c|}{26} & \multicolumn{2}{|c|}{25} & \multicolumn{2}{|c|}{21} \\
\hline Energy intake $(\mathrm{MJ} / \mathrm{d})$ & 6.2 & $2 \cdot 4$ & 6.8 & $2 \cdot 8$ & $6 \cdot 2$ & $2 \cdot 6$ & 6.6 & 1.7 \\
\hline Protein (\% energy) & 16.8 & $5 \cdot 0$ & 16.9 & $3 \cdot 6$ & 16.9 & $4 \cdot 8$ & 16.0 & $2 \cdot 9$ \\
\hline Fat (\% energy) & $36 \cdot 6$ & $7 \cdot 2$ & $34 \cdot 8$ & $7 \cdot 2$ & $36 \cdot 5$ & 9.6 & 33.7 & 7.5 \\
\hline
\end{tabular}

Mean values were significantly different from those at inclusion into the study: ${ }^{* *} P<0.01 ;{ }^{* * *} P<0.001$. $\dagger$ For details of subjects and procedures, see pp. 556-557.

\# The diet group followed a 'fasting' regimen for 7-10 d, a vegan diet for the next 3.5 months, and a lactovegetarian diet for the remainder of the study.

\section{Energy and fatty acid intake}

Total energy and fat intakes were reduced during the vegan and lactovegetarian diet periods (Table 1). The dietary intake of the saturated and monoenic fatty acids, except for 18:1, was significantly reduced during the vegan and the lactovegetarian diet periods. The intake of $18: 2 n-6$ was significantly increased during the vegan diet period and it constituted approximately $50 \%$ of the fatty acid intake during this period. In the control group the intake of $18: 2 n-6$ was increased during the convalescent home stay but during the remaining study period the fatty acid intake was unaltered (Table 2 ).

At the time of recruitment the intake of $20: 4 n-6$ was calculated to be $0 \cdot 14$ (range $0.0-0.41) \mathrm{g} / \mathrm{d}$ in the diet group, whereas during the vegan and lactovegetarian diet periods the calculated intake of this fatty acid was zero. The Norwegian Food Composition Tables do not give any values for 20:4n-6 in milk and dairy products, but the Norwegian Dairy Company (Norwegian Dairy Company, personal communication) estimates 20:4n-6 to constitute $0.003 \%$ of the fat content in milk. However, these values would be too minute to be registered in the database (i.e. $10 \mathrm{mg} 20: 4 n-6 / 1$ full-fat milk). In the control group the mean daily intake of $20: 4 n-6$ was $0 \cdot 12$ (range $0 \cdot 0-0 \cdot 35$ ) $\mathrm{g} / \mathrm{d}$.

At recruitment the ten patients who used cod-liver oil supplementation had a mean daily calculated intake of $20: 5 n-3$ of 0.44 (range $0-21-0.89$ ) $\mathrm{g} / \mathrm{d}$, whereas in the group not taking cod-liver oil supplementation the intake of $20: 5 n-3$ was 0.15 (range $0 \cdot 0-1 \cdot 81$ ) g/d. During the dietary treatment the five patients in the diet group taking cod-liver oil had an intake of $20: 5 n-3$ of $0.22 \mathrm{~g} / \mathrm{d}$, whereas the patients not taking cod-liver oil supplementation had an intake of $0.0 \mathrm{~g} / \mathrm{d}$.

The fatty acid profile in plasma phospholipids

The concentrations of most of the fatty acids were significantly reduced in plasma phospholipids after the vegan diet period (Table 3). After the lactovegetarian diet the concentrations of most of the fatty acids had returned to baseline values. The concentration of $18: 2 n-6$, however, was stable during the whole study period, and accordingly the 
Table 2. Intake of fatty acids $(\mathrm{g} / \mathrm{d})$ by rheumatoid arthritis patients following a vegetarian diet, compared with controls

(Mean values and standard deviations)

\begin{tabular}{|c|c|c|c|c|c|c|c|c|}
\hline & \multicolumn{2}{|c|}{$\underset{\text { inclusion }}{\text { At }}$} & \multicolumn{2}{|c|}{$\begin{array}{l}\text { After } \\
1 \text { month }\end{array}$} & \multicolumn{2}{|c|}{$\begin{array}{l}\text { After } \\
4 \text { months }\end{array}$} & \multicolumn{2}{|c|}{$\begin{array}{c}\text { After } \\
7-13 \text { months }\end{array}$} \\
\hline & Mean & SD & Mean & SD & Mean & SD & Mean & SD \\
\hline \multicolumn{9}{|l|}{ Diet group§ } \\
\hline$n$ & \multicolumn{2}{|c|}{27} & \multicolumn{2}{|c|}{27} & \multicolumn{2}{|c|}{26} & \multicolumn{2}{|c|}{23} \\
\hline $14: 0$ & 3.7 & $2 \cdot 1$ & $0 \cdot 1 \dagger$ & $0 \cdot 1$ & $0.6 \dagger$ & 1.6 & $2 \cdot 3 * *$ & $1 \cdot 7$ \\
\hline $16: 0$ & $13 \cdot 0$ & $4 \cdot 7$ & $3 \cdot 1 \dagger$ & $2 \cdot 3$ & $5 \cdot 9^{* * *}$ & $4 \cdot 5$ & $8 \cdot 2 * *$ & $4 \cdot 3$ \\
\hline $16: 1$ & 1.9 & 0.7 & $0.1 \dagger$ & 0.2 & $0.3+$ & $0 \cdot 4$ & $0.9^{* * * *}$ & 0.6 \\
\hline $18: 0$ & $6 \cdot 1$ & $2 \cdot 3$ & $1.6 \dagger$ & $1 \cdot 3$ & $3 \cdot 0 * * *$ & $2 \cdot 3$ & $3 \cdot 9 * * *$ & $2 \cdot 1$ \\
\hline $18: 1$ & $19 \cdot 1$ & $6 \cdot 6$ & $10 \cdot 6^{* *}$ & $8 \cdot 1$ & 16.4 & 11.9 & $14 \cdot 5^{* *}$ & $6 \cdot 3$ \\
\hline $18: 2 n-6$ & $7 \cdot 0$ & 3.0 & $18 \cdot 0^{* * *}$ & $17 \cdot 9$ & $22 \cdot 8 \dagger$ & $13 \cdot 6$ & $13 \cdot 2$ & $7 \cdot 5$ \\
\hline $18: 3 n-3$ & 1.0 & 0.6 & $1 \cdot 2$ & 1.4 & 1.4 & $1 \cdot 4$ & 1.0 & $1 \cdot 2$ \\
\hline Total SFA & $27 \cdot 9$ & $10 \cdot 7$ & $5 \cdot 0 \dagger$ & 3.7 & $10 \cdot 4 * * *$ & 9.9 & $17 \cdot 4^{* * *}$ & 9.9 \\
\hline Total MUFA & $24 \cdot 2$ & $7 \cdot 4$ & $11.0 \dagger$ & $8 \cdot 4$ & $17 \cdot 0^{* *}$ & $12 \cdot 3$ & $16 \cdot 7^{* *}$ & $7 \cdot 2$ \\
\hline Total PUFA & $9 \cdot 6$ & $3 \cdot 8$ & $19 \cdot 6^{* *}$ & $18 \cdot 5$ & $24 \cdot 4 * * *$ & $14 \cdot 4$ & $14 \cdot 9$ & 8.0 \\
\hline \multicolumn{9}{|l|}{ Control group } \\
\hline$n$ & \multicolumn{2}{|c|}{26} & \multicolumn{2}{|c|}{26} & \multicolumn{2}{|c|}{25} & \multicolumn{2}{|c|}{21} \\
\hline $14: 0$ & 3.4 & 1.6 & $3 \cdot 6$ & 1.9 & 3.4 & $1 \cdot 8$ & $3 \cdot 3$ & 1.4 \\
\hline $16: 0$ & $11 \cdot 0$ & $3 \cdot 2$ & $12 \cdot 3$ & $6 \cdot 6$ & $11 \cdot 5$ & $6 \cdot 2$ & $11 \cdot 1$ & 4.5 \\
\hline $16: 1$ & 1.9 & 0.7 & 1.9 & $1 \cdot 2$ & $1 \cdot 7$ & 0.9 & 1.9 & 0.8 \\
\hline $18: 0$ & $4 \cdot 9$ & 1.7 & $5 \cdot 7$ & $3 \cdot 2$ & $5 \cdot 3$ & $3 \cdot 3$ & 49 & $2 \cdot 1$ \\
\hline $18: 1$ & $15 \cdot 6$ & $5 \cdot 3$ & $17 \cdot 8$ & 11.9 & $16 \cdot 4$ & $10 \cdot 1$ & $14 \cdot 9$ & 6.7 \\
\hline $18: 2 n-6$ & 6.0 & $4 \cdot 7$ & $9 \cdot 9^{* *}$ & 11.9 & 6.2 & 5.8 & $6 \cdot 1$ & $3 \cdot 3$ \\
\hline $18: 3 n-3$ & 0.8 & 0.6 & 1.0 & 0.8 & 0.9 & 0.8 & 0.9 & 0.5 \\
\hline Total SFA & $23 \cdot 9$ & $8 \cdot 3$ & $26 \cdot 3$ & $13 \cdot 7$ & $24 \cdot 6$ & $13 \cdot 1$ & $23 \cdot 0$ & 8.9 \\
\hline Total MUFA & $20 \cdot 9$ & $7 \cdot 5$ & $22 \cdot 8$ & $14 \cdot 5$ & $21 \cdot 1$ & $11 \cdot 8$ & $21 \cdot 0$ & $9 \cdot 6$ \\
\hline Total PUFA & $8 \cdot 8$ & $6 \cdot 0$ & $9 \cdot 7$ & $7 \cdot 9$ & $9-0$ & $7 \cdot 1$ & $9-9$ & $5 \cdot 6$ \\
\hline
\end{tabular}

SFA, saturated fatty acids; MUFA, monounsaturated fatty acids; PUFA, polyunsaturated fatty acids.

Mean values were significantly different from those at inclusion into the study. ${ }^{* *} P<0.01 ;{ }^{* * *} P<0.001$; $\dagger P<0.0001$.

\$ For details of subjects and procedures, see pp. 556-557.

$\S$ The diet group followed a 'fasting' regime for $7-10 \mathrm{~d}$, a vegan diet for the next 3.5 months, and a lactovegetarian diet for the remainder of the study.

proportion of this fatty acid increased significantly (Table 4). The concentrations as well as the proportions of $20: 5 n-3$ and $22: 6 n-3$ were reduced during the study period. The concentration of $20: 4 n-6$ was significantly reduced after the vegan diet periods, but was increased again after the lactovegetarian diet. However, the proportion of 20:4n-6 was not changed during the study period. In the control group the total amount of fatty acids in the plasma phospholipid fraction was stable during the whole study period (data not shown).

The patients who used cod-liver oil supplementation had significantly higher concentrations of $20: 5 n-3$ and $22: 6 n-3$ in the phospholipid fraction compared with the patients who did not supplement their diet with cod-liver oil ( $P=0.02$ for both fatty acids). However, there was no difference in the disease activity variables between the group who took cod-liver oil supplementation and those who did not, either at the time of inclusion or at any of the subsequent clinical evaluations (data not shown).

Ten patients in the diet group used linseed oil during the vegan diet period. These patients had a higher concentration of $18: 3 n-3$ after the health farm stay $(P<0.001)$, but this difference was not detectable after 3 months on a vegan diet. 
Table 3. Fatty acid composition of plasma phospholipids (mmol/l) in rheumatoid arthritis patients consuming vegan and lactovegetarian diets§"

(Mean values and standard deviations)

\begin{tabular}{|c|c|c|c|c|c|c|c|c|}
\hline \multirow[b]{2}{*}{ Fatty acid } & \multicolumn{2}{|c|}{$\begin{array}{l}\text { At } \\
\text { inclusion } \\
(n 27)\end{array}$} & \multicolumn{2}{|c|}{$\begin{array}{l}\text { After the } \\
\text { health farm stay } \\
\text { ( } n 27)\end{array}$} & \multicolumn{2}{|c|}{$\begin{array}{l}\text { After the } \\
\text { vegan diet } \\
(n 26)\end{array}$} & \multicolumn{2}{|c|}{$\begin{array}{c}\text { After the } \\
\text { lactovegetarian diet } \\
(n \text { 23) }\end{array}$} \\
\hline & Mean & SD & Mean & SD & Mean & SD & Mean & SD \\
\hline $14: 0$ & 4.5 & 1.6 & $2.5 t$ & 0.8 & $3 \cdot 1 * * *$ & $1 \cdot 1$ & $4 \cdot 5$ & $1 \cdot 6$ \\
\hline $16: 0$ & $308 \cdot 3$ & $53 \cdot 4$ & $279 \cdot 2 * * *$ & $49 \cdot 4$ & $254 \cdot 1 \dagger$ & $44 \cdot 6$ & $288-2$ & 57.6 \\
\hline $16: 1$ & $5 \cdot 5$ & $2 \cdot 3$ & $4 \cdot 9 * * *$ & 1.6 & $4.0 t$ & 1.4 & $5 \cdot 2$ & $2 \cdot 4$ \\
\hline $18: 0$ & $162 \cdot 3$ & $26 \cdot 2$ & $137 \cdot 2 \dagger$ & $25 \cdot 5$ & $134 \cdot 3 \dagger$ & 16.9 & $150 \cdot 1$ & $30 \cdot 5$ \\
\hline $18: 1$ & 114.0 & 25.9 & $93.4^{* * *}$ & 18.7 & $84.6 \dagger$ & 16.6 & $95 \cdot 7^{* *}$ & $23 \cdot 4$ \\
\hline $18: 2 n-6$ & 247.9 & $53 \cdot 5$ & 248.9 & 43.9 & 253.9 & 48.9 & $259 \cdot 7$ & 59.8 \\
\hline $18: 3 n-3$ & 2.5 & 0.7 & 1.9 & $2 \cdot 1$ & $2 \cdot 0^{* *}$ & $1 \cdot 2$ & 2.5 & 1.0 \\
\hline $20: 0$ & $8 \cdot 3$ & $1 \cdot 5$ & $8 \cdot 3$ & $2 \cdot 1$ & 7.7 & 1.6 & $8 \cdot 1$ & 1.6 \\
\hline $20: 1$ & $3 \cdot 4$ & 1.6 & $2 \cdot 4^{* * *}$ & $1 \cdot 2$ & $2 \cdot 3 * * *$ & 0.7 & $2 \cdot 6^{* *}$ & 1.4 \\
\hline $20: 3 n-9$ & $2 \cdot 3$ & $1 \cdot 1$ & $0.6 \dagger$ & 0.7 & $0.6 \dagger$ & 0.6 & $1 \cdot 6^{* *}$ & $1 \cdot 1$ \\
\hline $20: 2 n-6$ & 6.0 & 1.4 & $4 \cdot 7^{* * *}$ & $1 \cdot 1$ & $5 \cdot 5$ & $1 \cdot 6$ & $6 \cdot 2$ & 1.8 \\
\hline $20: 3 n-6$ & $36 \cdot 5$ & $10 \cdot 0$ & $19.5 t$ & 5.8 & $25.5 \dagger$ & 6.8 & $36 \cdot 1$ & 10.6 \\
\hline $20: 4 n-6$ & 102.5 & $23 \cdot 3$ & $93.9 * *$ & $29 \cdot 2$ & $87 \cdot 2^{* *}$ & $24 \cdot 4$ & 95.9 & $23 \cdot 9$ \\
\hline $20: 5 n-3 \rrbracket$ & $22 \cdot 7$ & $11 \cdot 2$ & $8 \cdot 2 \dagger$ & 5.8 & $8.4 \dagger$ & $5 \cdot 2$ & $17 \cdot 4^{* *}$ & $13 \cdot 4$ \\
\hline $22: 0$ & 29.5 & 6.2 & $21.7 \dagger$ & $4 \cdot 8$ & $24 \cdot 3^{* *}$ & 4.8 & $27 \cdot 1$ & 5.8 \\
\hline $22: \ln -11$ & $9 \cdot 7$ & $4 \cdot 2$ & $4.8 \dagger$ & 2.9 & $3.9+$ & 3.5 & $6 \cdot 2^{* *}$ & $3 \cdot 5$ \\
\hline $22: \ln -9$ & $3 \cdot 1$ & $1 \cdot 4$ & $1.8 * * *$ & 1.5 & $1.9+$ & $1 \cdot 2$ & $2 \cdot 3^{* *}$ & $1 \cdot 2$ \\
\hline $22: 4 n-6$ & $3 \cdot 3$ & $2 \cdot 4$ & $1 \cdot 6^{* * *}$ & $1 \cdot 2$ & $1 \cdot 1 * * *$ & $1 \cdot 1$ & $2 \cdot 3$ & $2 \cdot 0$ \\
\hline $22: 5 n-6$ & 1.8 & 0.7 & $1 \cdot 5^{* *}$ & 0.8 & $1 \cdot 3 * *$ & 0.8 & 1.9 & 1.2 \\
\hline $22: 5 n-39$ & $15 \cdot 7$ & $3 \cdot 4$ & $14 \cdot 3 * *$ & 3.6 & $14 \cdot 2 * *$ & 3.0 & 16.6 & $4 \cdot 7$ \\
\hline $22: 6 n-3 \pi$ & $78 \cdot 2$ & $19 \cdot 7$ & $66 \cdot 7^{* *}$ & $20 \cdot 1$ & $54 \cdot 1 \dagger$ & $16 \cdot 0$ & $66 \cdot 1 * *$ & $22 \cdot 6$ \\
\hline $24: 0$ & 13.8 & 30 & $11 \cdot 7^{* * *}$ & $2 \cdot 8$ & $14 \cdot 6$ & 3.0 & $14 \cdot 5$ & $4 \cdot 1$ \\
\hline $24: 1$ & $30 \cdot 2$ & $4 \cdot 8$ & $35 \cdot 0^{* *}$ & $9 \cdot 3$ & $31 \cdot 0$ & 8.6 & $28 \cdot 5$ & 6.8 \\
\hline Total $(n-6)$ & $408 \cdot 0$ & $75 \cdot 3$ & $369 \cdot 4^{* *}$ & $56 \cdot 3$ & $374 \cdot 3 \ddagger$ & 60.5 & $402 \cdot 3$ & $81 \cdot 7$ \\
\hline Total $(n-3)$ & $133 \cdot 1$ & $42 \cdot 5$ & $109 \cdot 3 \dagger$ & $45 \cdot 6$ & $92 \cdot 4 \dagger$ & $37 \cdot 4$ & $92.5 \dagger$ & $30 \cdot 6$ \\
\hline Total saturated & $526 \cdot 7$ & 84.9 & $460 \cdot 7 \dagger$ & $76 \cdot 1$ & $438 \cdot 2 \dagger$ & $57 \cdot 3$ & $492 \cdot 7$ & 91.9 \\
\hline
\end{tabular}

Mean values were significantly different from those at inclusion into the study: ${ }^{* *} P<0.01 ; * * * P<0.001$; $\dagger P<0.0001 ; \ddagger P=0.02$.

$\S$ For details of subjects and procedures, see pp. 556-557.

The patients followed a 'fasting' regimen for 7-10 d, a vegan diet for the next 3.5 months and a lactovegetarian diet for the remainder of the study.

ff Only the patients who did not take cod-liver oil supplements.

\section{$T B A R S$}

Because the concentration of TBARS was significantly different between the patient groups at baseline ANACOVA test was used with the baseline values as covariate. ANACOVA revealed that there was an overall significant reduction in the concentration of TBARS in the diet group compared with the control group during the study period $(P=0.03$; Table 5). The TBARS were not significantly different in the diet responder group compared with the diet non-responder group.

\section{Association between fatty acid concentration and disease activity}

No significant differences were found in fatty acid concentrations between diet responders and diet non-responders. ANACOVA was used to investigate if the concentration of the fatty acids in plasma phospholipids varied in accordance with disease activity variables 
Table 4. Percentage distribution of fatty acids in plasma phospholipids in rheumatoid arthritis patients consuming vegan and lactovegetarian diets $\$ \S$

(Mean values and standard deviations)

\begin{tabular}{|c|c|c|c|c|c|c|c|c|}
\hline \multirow[b]{2}{*}{ Fatty acid } & \multicolumn{2}{|c|}{$\begin{array}{c}\text { At } \\
\text { inclusion } \\
(n \text { 27) }\end{array}$} & \multicolumn{2}{|c|}{$\begin{array}{l}\text { After the } \\
\text { health farm stay } \\
(n 27)\end{array}$} & \multicolumn{2}{|c|}{$\begin{array}{l}\text { After the } \\
\text { vegan diet } \\
(n 26)\end{array}$} & \multicolumn{2}{|c|}{$\begin{array}{l}\text { After the } \\
\text { lactovegetarian diet } \\
(n \text { 23) }\end{array}$} \\
\hline & Mean & SD & Mean & SD & Mean & SD & Mean & SD \\
\hline $14: 0$ & $0 \cdot 36$ & $0 \cdot 36$ & $0.23+$ & 0.06 & $0 \cdot 30^{* *}$ & $0 \cdot 12$ & 0.38 & 0.11 \\
\hline $16: 0$ & $24 \cdot 85$ & 0.98 & $25 \cdot 81^{* *}$ & $1 \cdot 24$ & $24 \cdot 51$ & 1.68 & $25 \cdot 03$ & $1 \cdot 11$ \\
\hline $16: 1$ & $0 \cdot 45$ & 0.14 & $0-45$ & 0.12 & $0 \cdot 39^{* *}$ & $0 \cdot 11$ & 0.44 & 0.16 \\
\hline $18: 0$ & $13 \cdot 19$ & 0.69 & $12 \cdot 71$ & $1 \cdot 18$ & $13 \cdot 01$ & $1 \cdot 16$ & $13 \cdot 06$ & 0.79 \\
\hline $18: 1$ & $9 \cdot 18$ & 1.23 & $8 \cdot 64$ & $1 \cdot 10$ & $8 \cdot 18$ & $1 \cdot 14$ & 8.41 & $1 \cdot 30$ \\
\hline $18: 2 n-6$ & $20-97$ & $3 \cdot 23$ & $23 \cdot 31^{* *}$ & 4.47 & $24 \cdot 71 \dagger$ & $4 \cdot 26$ & $22 \cdot 72^{* *}$ & $3 \cdot 43$ \\
\hline $18: 3 n-3$ & $0 \cdot 20$ & 0.05 & 0.18 & 0.22 & $0 \cdot 19$ & 0.11 & $0 \cdot 21$ & 0.08 \\
\hline $20: 0$ & 0.68 & $0 \cdot 10$ & $0.76^{* *}$ & $0 \cdot 13$ & $0.75^{* *}$ & $0 \cdot 13$ & 0.73 & $0 \cdot 11$ \\
\hline $20: 1$ & 0.27 & $0 \cdot 10$ & $0.21 * *$ & 0.08 & $0 \cdot 22 * *$ & $0 \cdot 11$ & 0.23 & $0 \cdot 11$ \\
\hline $20: 3 n-9$ & $0 \cdot 18$ & 0.08 & $0.05 \dagger$ & 0.06 & $0.05 \dagger$ & 0.05 & $0 \cdot 12^{* *}$ & 0.08 \\
\hline $20: 2 n-6$ & 0.48 & 0.07 & $0.44^{* *}$ & 0.09 & 0.54 & $0 \cdot 10$ & $0.55^{* *}$ & 0.11 \\
\hline $20: 3 n-6$ & $2 \cdot 94$ & 0.61 & $1.80 \dagger$ & 0.41 & $2 \cdot 48^{* *}$ & 0.64 & $3 \cdot 13$ & 0.64 \\
\hline $20: 4 n-6$ & $8 \cdot 32$ & $1 \cdot 19$ & $8 \cdot 56$ & 1.76 & $8 \cdot 40$ & 1.77 & $8 \cdot 36$ & $1 \cdot 38$ \\
\hline $20: 5 n-3^{\|}$ & $1 \cdot 86$ & 1.00 & $0.76+$ & 0.44 & $0 \cdot 81^{* * *}$ & 0.45 & $1.48^{* *}$ & 0.98 \\
\hline $22: 0$ & $2 \cdot 41$ & 0.39 & $2 \cdot 00 \dagger$ & 0.32 & $2 \cdot 38$ & 0.49 & 2.43 & 0.50 \\
\hline $22: 1 n-11$ & 0.79 & 0.31 & $0.43 \dagger$ & 0.24 & $0.38 \uparrow$ & 0.32 & $0.53^{* *}$ & 0.34 \\
\hline $22: 1 n-9$ & 0.25 & $0 \cdot 11$ & $0 \cdot 16^{* *}$ & 0.12 & $0 \cdot 11 \dagger$ & 0.11 & $0 \cdot 19$ & 0.11 \\
\hline $22: 4 n-6$ & 0.26 & 0.17 & $0 \cdot 14^{* * *}$ & 0.11 & $0.09 * * *$ & 0.09 & $0 \cdot 18$ & 0.13 \\
\hline $22: 5 n-6$ & 0.14 & 0.05 & $0 \cdot 13$ & 0.06 & 0.12 & 0.07 & $0 \cdot 16$ & 0.09 \\
\hline $22: 5 n-3^{4}$ & $1 \cdot 35$ & 0.21 & 1.40 & 0.19 & 1.44 & 0.26 & $1 \cdot 38$ & $0 \cdot 21$ \\
\hline $22: 6 n-3^{\|}$ & $6 \cdot 58$ & $1 \cdot 60$ & $6 \cdot 33$ & $1 \cdot 27$ & $5 \cdot 80^{* *}$ & $1 \cdot 27$ & $5.88^{* *}$ & 1.71 \\
\hline $24: 0$ & $1 \cdot 13$ & 0.25 & $1 \cdot 09$ & $0 \cdot 21$ & $1.45 \dagger$ & $0 \cdot 35$ & $1 \cdot 31^{* *}$ & $0 \cdot 38$ \\
\hline $24: 1$ & $2 \cdot 47$ & 0.42 & $3.21 \dagger$ & 0.52 & $3 \cdot 00 * *$ & 0.72 & $2 \cdot 54$ & 0.62 \\
\hline
\end{tabular}

Mean values were significantly different from those at inclusion into the study: ${ }^{* *} P<0.01$; $* * * P<0.001$; $\dagger P<0.0001$.

$¥$ For details of subjects and procedures, see pp. $556-557$.

$\S$ The patients followed a 'fasting' regimen for $7-10 \mathrm{~d}$, a vegan diet for the next 3.5 months and a lactovegetarian diet for the remainder of the study.

"I Only the patients who did not take cod-liver oil supplements.

during the study. The concentrations of $20: 4 n-6$ and $20: 3 n-6$ were inversely associated with the number of swollen joints ( $P=0.05$ and $P=0.01$ respectively).

\section{DISCUSSION}

We have conducted a clinical trial in which RA patients treated with a fast and a 1-year vegetarian diet improved significantly compared with RA patients using an omnivorous diet (Kjeldsen-Kragh et al. 1991). Since it has been shown that the inflammatory process can be modulated through fatty acid supplementation in patients with RA (Cleland et al. 1988; Baker et al. 1989; Tate et al. 1989), it is possible that the altered fatty acid profile following vegetarian diets (Phinney et al. 1990) can explain the measured improvement.

Non-steroidal anti-inflammatory drugs (NSAIDs) are commonly used in the treatment of RA patients. As these drugs inhibit the production of prostaglandins it could be envisaged that treatment with such drugs may influence the concentration of fatty acids in the plasma phospholipids. Eleven patients did not use NSAIDs medication during the 
Table 5. Concentration of thiobarbituric acid-reacting substances (TBARS) in the plasma of patients with rheumatoid arthritis consuming a vegetarian diet, compared with controls $* \dagger$

(Mean values and standard deviations)

\begin{tabular}{|c|c|c|c|c|}
\hline & \multicolumn{4}{|c|}{ TBARS $(\mu \mathrm{mol} / 1)$} \\
\hline & \multicolumn{2}{|c|}{ Diet group $\ddagger$} & \multicolumn{2}{|c|}{ Control group } \\
\hline & Mean & SD & Mean & SD \\
\hline At inclusion & $4 \cdot 39$ & $2 \cdot 42$ & $5 \cdot 53$ & $1 \cdot 83$ \\
\hline After 1 month & $4 \cdot 53$ & 2.76 & $5 \cdot 39$ & $2 \cdot 16$ \\
\hline After 4 months & $4 \cdot 02$ & 1.83 & 5.97 & 2.46 \\
\hline After 7-13 months & 3.83 & $2 \cdot 08$ & 4.96 & 2.87 \\
\hline
\end{tabular}

* For details of subjects and procedures, see pp. 556-557.

$\dagger$ Patients in the diet group followed a 'fasting' regimen for $7-10 \mathrm{~d}$, a vegan diet for the next 3.5 months and a lactovegetarian diet for the remainder of the study,

$\ddagger$ Overall difference between the diet group and the control group, $P=0.03$ (ANACOVA).

study period. Five patients reduced and one patient increased their intake of NSAID along the study course (Kjeldsen-Kragh et al. 1991). However, there was no significant difference with regard to fatty acid concentration or lipid peroxidation products between the patients who used NSAID and those who did not. The simultaneous use of corticosteroids (five patients), second-line drugs (four patients) and cyostatic drugs (two patients) might have obscured this result. As this was a longitudinal study and since the use of drugs was kept constant, except for the six patients, the measured within-group differences most likely express changes in the diet.

Increased intake of $18: 2 n-6$ in the diet group did not result in an increased concentration of this fatty acid in the plasma phospholipids. The proportion of $18: 2 n-6$, however, was significantly increased both after the vegan and the lactovegetarian diet periods (Table 4). Neither the concentration nor the proportion of $18: 2 n-6$ was different in diet responders compared with diet non-responders and no association was found between this fatty acid and the disease activity variables. Therefore, an increased intake of $18: 2 n-6$ does not seem to have any impact on disease activity in patients with RA. This result agrees with the conclusions of two other studies, where RA patents were treated with $18: 2 n-6$ (Jäntti et al. 1985; Sköldstam et al. 1988).

Another way in which a vegetarian diet could have an impact on the inflammatory process in RA is through a reduced availability of $20: 4 n-6$. The main source of this fatty acid in Western communities is the diet (Phinney et al. 1990; Adam, 1992). During a vegan diet period, which is devoid of $20: 4 n-6$, and during a lactovegetarian diet period, which may only supply trace amounts of $20: 4 n-6$, tissue $20: 4 n-6$ must be supplied through endogenous production. This production of $20: 4 n-6$ from $18: 2 n-6$ is dependent on the activity of delta- 6 and delta- 5 desaturase enzymes. It has been shown that an intake of $20 \mathrm{~g}$ $18: 2 n-6 / \mathrm{d}$ inhibits the delta-6 desaturase activity (Adam, 1992). This would imply a reduced production of $20: 4 n-6$ during the vegan diet period, since the mean dietary intake of $18: 2 n-6$ exceeded this amount. The plasma concentration of phospholipid 20:4n-6 was significantly decreased during the vegan diet period but the proportion of $20: 4 n-6$ in plasma phospholipids was unchanged. The observation that the concentration of $20: 4 n-6$ was inversely associated with the number of swollen joints would also argue against an 
impaired capacity to form arachidonic acid as an explanation for the decreased disease activity with the vegetarian diet treatment.

Several studies have found that relatively high intakes $(>2 \mathrm{~g} / \mathrm{d})$ of $20: 5 n-3$ and $22: 6 n-3$ lead to mild symptomatic improvement in RA (Kremer et al. 1987). In the present study the proportions of $20: 5 n-3$ and $22: 6 n-3$ fell during the vegan diet even though the proportion of $18: 3 n-3$ was unchanged in the plasma phospholipids. This is in agreement with previous studies (Sanders et al. 1978) that reported lower proportions of $20: 5 n-3$ and $22: 6 n-3$ in vegans compared with omnivores. Despite the absence of $20: 5 n-3$ and 22:6n-3 fatty acids in the vegan diet, disease activity was reduced in the patients. Neither were there significant differences in the plasma phospholipid concentrations of $n-3$ fatty acids between responders and non-responders.

A significant reduction in TBARS in the diet group compared with the control group agrees with findings from patients with fibromyalgia who fasted and used a vegetarian diet for 3 weeks (Høstmark et al. 1993). It is possible that the reduced malonaldehyde measured during the vegetarian diets could be an indicator of reduced eicosanoid formation. However, since there was no significant difference in the concentration of TBARS between the diet responder group and the diet non-responder group this may reflect a high intake of antioxidants, such as $\alpha$-tocopherol and $\beta$-carotene, and/or a low fat intake (Table 1) with the vegetarian diets, rather than a reduced production following reduced disease activity.

In conclusion, the alterations of the fatty acid profiles in plasma phospholipids as a result of a vegan and a lactovegetarian diet were extensive in patients with RA. However, the clinical improvement could not be attributed to the changes in plasma phospholipid fatty acids.

This study was made possible with grants from The Norwegian Women's Public Health Association, The Anders Jahres Legacy, The Grethe Harbitz Legacy, The Eckbo Legacy and The Olga Imerslund Legacy. The skilled technical assistance of Merete Mack, Sylvia Nome Kvam and Ida Goffeng Bay are gratefully acknowledged.

\section{REFERENCES}

Abdulla, M., Andersson, I., Asp, N.-G., Berthelsen, K., Birkhed, D., Dencker, I., Johansson, C.-G., Jägerstad, M., Kolar, K., Nair, B M., Nilsson-Ehle, P., Norden, A, Rassner, S., Åkesson, B. \& Öckerman, P.-A. (1981). Nutrient intake and health status of vegans. Chemical analyses of diets using the duplicate portion sampling technique. American Journal of Clinical Nutrition 34, 2464-2477.

Adam, O. (1992). Immediate and long range effects of the uptake of increased amounts of arachidonic acid. Clinical Investigator 70, 721-727.

Baker, D. G., Krakauer, K. A., Tate, G., Laposata, M. \& Zurier, R. B. (1989). Suppression of human synovial cell proliferation by dihomogamma-linolenic acid. Arthritis and Rheumatism 32, 1273-1281.

Belch, J. J. F., Ansell, D., Madhok, R., O'Dowd, A. \& Sturrock, R. D. (1988). Effects of altering dietary essential fatty acids on requirements for non-steroidal anti-inflammatory drugs in patients with rheumatoid arthritis: a double blind placebo controlled study. Annals of the Rheumatic Diseases 47, 96-104.

Bønaa, K. H., Bjerve, K., Straume, B., Gram, I. T. \& Thelle, D. (1990). Effects of eicosapentaenoic and docosahexaenoic acids on blood pressure in hypertension. New England Journal of Medicine 322, $795-801$.

Bruderlein, H., Daniel, R., Boismenu, D., Julien, N. \& Couture, F. (1981). Fatty acid profiles of serum phospholipids in patients suffering rheumatoid arthritis. Progress in Lipid Research 20, 625-631.

Brzeski, M., Madhok, R. \& Capell, H. A. (1991). Evening primrose oil in patients with rheumatoid arthritis and side-effects of non-steroidal antiinflammatory drugs. British Journal of Rheumatology 30, 370-372.

Cleland, L. G., French, J. K., Betts, W. H., Murphy, G. A. \& Elliott, M. J. (1988). Clinical and biochemical effects of dietary fish oil supplements in rheumatoid arthritis. Journal of Rheumatology 15, 1471-1475.

Endres, S., Ghorbani, R., Kelley, V. \& Dinarello, C. A. (1989). The effect of dietary supplementation with n-3 polyunsaturated fatty acids on the synthesis of interleukin-1 and tumor necrosis factor by mononuclear cells. New England Journal of Medicine 320, 265-271.

Fries, J. F., Spitz, P., Kraines, R. G. \& Holman, H. R. (1980). Measurement of patient outcome in arthritis. Arthritis and Rheumatism 23, 137-145. 
Gronn, M., Gørbitz, C., Christensen, E., Levorsen, A., Ose, L., Hagve, T.-A. \& Christophersen, B. O. (1991). Dietary n-6 fatty acids inhibit the incorporation of dietary n-3 fatty acids in thrombocyte and serum phospholipids in humans: a controlled dietetic study. Scandinavian Journal of Clinical and Laboratory Investigation 51, 255-263.

Haugen, M., Høyeraal, H. M., Larsen, S., Gilboe, I.-M. \& Trygg, K. (1992). Nutrient intake and nutritional status in children with juvenile chronic arthritis. Scandinavian Journal of Rheumatology 21, 165-170.

Hestmark, A. T., Lystad, E., Vellar, O. D., Hovi, K. \& Berg, J. E. (1993). Reduced plasma fibrinogen, serum peroxides, lipids, and apolipoproteins after a 3-week vegetarian diet. Plant Foods for Human Nutrition $\mathbf{4 3}$ 55-61.

Jacobsson, L., Lindgärde, R., Manthorpe, R. \& Åkesson, B. (1990). Correlation of fatty acid composition of adipose tissue lipids and serum phosphatidylcholine and serum concentrations of micronutrients with disease duration in rheumatoid arthritis. Annals of the Rheumatic Diseases 49, 901-905.

Jäntti, J., Isomäki, H., Laitinen, O., Nikkari, T., Seppälä, E. \& Vapaatalo, H. (1985). Linoleic acid treatment in inflammatory arthritis. International Journal of Clinical Pharmacology, Therapy and Toxicity 23, 89-91.

Johansson, U., Portinsson, S., Åkesson, A., Svantesson, H. \& Åkesson, B. (1986). Fatty acid composition of plasma phosphatidylcholine and erythrocyte lipids, and dietary fat intake in juvenile chronic arthritis. Progress in Lipid Research 25, 579-582.

Kirkeby, K. \& Bjerkedal, I. (1968). The fatty acid composition in serum of Norwegian vegetarians. Acta Medica Scandinavica 183, 143-148.

Kjeldsen-Kragh, J., Haugen, M., Borchgrevink, C. F., Lærum, E., Eek, M., Mowinkel, P., Hovi, K. \& Førre, Ø. (1991). Controlled trial of fasting and one-year vegetarian diet in rheumatoid arthritis. Lancet 338, 899-902.

Kjeldsen-Kragh, J., Lund, J. A., Riise, T., Finnanger, B., Haaland, K., Finstad, R., Mikkelsen, R. \& Førre, $\varnothing$ (1992). Dietary omega-3 fatty acid supplementation and Naproxen treatment in patients with rheumatoid arthritis. Journal of Rheumatology 19, 1531-1536.

Kleinbaum, D. G., Kupper, L. L. \& Müller, K. E. (1988). Applied Regression Analyses and Other Multivariable Methods, pp. 96-314. Boston: PWS-KENT Publishing Company.

Kosugi, H., Kojima, T. \& Kikugawa, K. (1989). Thiobarbituric acid-reactive substances from peroxidized lipids Lipids 24, 873-881.

Kowsari, B., Finnie, S. K., Carter, R. L., Love, J., Katz, P., Longley, S. \& Panush, R. S. (1983). Assessment of the diet of patients with rheumatoid arthritis and osteoarthritis. Journal of the American Dietetic Association $\mathbf{8 2}$, $657-659$.

Kremer, J. M., Jubiz, W., Michalek, A., Rynes, R. I., Bartholomew, L. E., Bigaouette, J., Timchalk, J. M., Beeler, D. \& Lininger, L. (1987). Fish oil supplementation in active rheumatoid arthritis: a double-blinded, controlled, crossover study. Annals of Internal Medicine 106, 497-503.

Linos, A., Kaklamanis, E., Kontomerkos, A., Koumantak, Y., Gazi, G., Vaiopoulos, G., Tsokos, G. C. \& Kaklamanis, P. (1991). The effect of olive oil and fish consumption on rheumatoid arthritis - a case control study. Scandinavian Journal of Rheumatology 20, 419-426.

Lunec, J., Halloran, S. P., White, A. G. \& Dormandy, L. (1981). Free-radical oxidation (peroxidation) products in serum and synovial fluid in rheumatoid arthritis. Journal of Rheumatology 8, 233-245.

Montgomery, D. C. (1984). Design and Analysis of Experiments, pp. 117-131. New York: John Wiley.

Paulus, H. E., Egger, M. J., Ward, J. R., Williams, H. J. \& The Cooperative Systematic Studies of Rheumatoid Diseases Group (1990). Analysis of improvement in individual rheumatoid arthritis patients treated with disease-modifying antirheumatic drugs, based on the findings in patients treated with placebo. Arthritis and Rheumatism 33, 477-484.

Phinney, S. D., Odin, R. S., Johnson, S. B. \& Holman, R. T. (1990). Reduced arachidonate in serum phospholipids and cholesteryl esters associated with vegetarian diets in humans. American Journal of Clinical Nutrition $\mathbf{5 1}$, 385-392.

Pullman-Mooar, S., Laposata, M., Lem, D., Holman, R. T., Leventhal, L. J., DeMarco, D. \& Zurier, R. B. (1990). Alteration of cellular fatty acid profile and the production of eicosanoids in human monocytes by gamma-linolenic acid. Arthritis and Rheumatism 33, 1526-1533.

Ropes, M. W., Bennet, G. A., Cobb, S., Jacox, R. \& Jessar, R. A. (1958). 1958 revision of diagnostic criteria for rheumatoid arthritis. Bulletin on the Rheumatic Diseases 9, 175-176.

Roshanai, F. \& Sanders, T. A. B. (1984). Assessment of fatty acids intake in vegans and omnivores. Human Nutrition: Applied Nutrition 38, 345-354.

Rowley, D., Gutteridge, J. M. C., Blake, D., Farr, M. \& Halliwell, B. (1984). Lipid peroxidation in rheumatoid arthritis: thiobarbituric acid-reactive material and catalytic iron salts in synovial fluid from rheumatoid patients. Clinical Science 66, 691-695.

Sanders, T. A. B., Ellis, F, R. \& Dickerson, J. W. T. (1978). Studies of vegans: the fatty acid composition of plasma choline phosphoglycerides, erythrocytes, adipose tissue, and breast milk, and some indicators of susceptibility to ischemic heart disease in vegans and omnivore controls. American Journal of Clinical Nutrition 31, 805 813.

Sanders, T. A. B. \& Roshanai, F. (1992). Platelet phospholipid fatty acid composition and function in vegans compared with age- and sex-matched omnivore controls. European Journal of Clinical Nutrition 46, 823-831.

Santoli, D., Phillips, P. D., Colt, T. L. \& Zurier, R. B. (1990). Suppression of interleukin 2-dependent human T 
cell growth in vitro by prostaglandin E (PGE) and their precursor fatty acids. Journal of Clinical Investigation 85, 424-432.

Sköldstam, L., Eriksson, Å. \& Berglund, U. (1988). Rheumatoid arthritis (RA) and polyunsaturated fat. Scandinavian Journal of Rheumatology Suppl. 72, 16.

Statens Ernæringsråd (1988). Matraretabell (The Norwegian Food Composition Tables), 5th ed. Oslo: Lands foreningen for Kosthold \& Helse.

Tate, T., Mandell, B. F., Laposata, M., Ohliger, D., Baker, D. G., Schumacher, H. R. \& Zurier, R. B. (1989). Suppression of acute and chronic inflammation by dietary gamma linolenic acid. Journal of Rheumatology 16, 729-734.

Tugwell, P., Boers, M. \& the OMERACT Committee (1993). Developing consensus on preliminary core efficacy endpoints for rheumatoid arthritis clinical trials. Journal of Rheumatology 20, 555-556.

Vossen, R. C. R. M., Feijge, M. A. H., Heemskerk, J. W. M., van Dam-Mieras, M. C. E., Hornstra, G. \& Zwaal, R. F. A. (1993). Long-term fatty acid modification of endothelial cells: implications for arachidonic acid distribution in phospholipid classes. Journal of Lipid Research 34, 409-420.

Ziff, M. (1983). Diet in the treatment of rheumatoid arthritis. Arthritis and Rheumatism 26, $457-461$. 